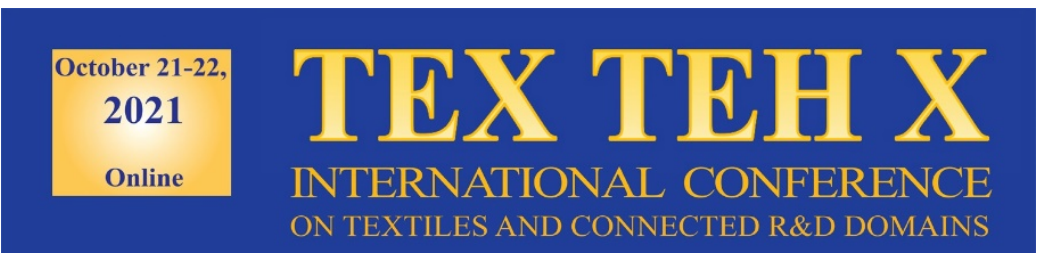

\title{
OPTIMIZATION OF SOME WEAVING MACHINE PARTS DESIGN. THEORETICAL APPROACH
}

\author{
DOI: 10.35530/TT.2021.33
}

\author{
A. Mostafa*1, W. Hashima ${ }^{1}$, S. El-Gholmy ${ }^{1}$, A. Al-Oufy ${ }^{1,3}$, M. Hassan ${ }^{2}$ \\ ${ }^{1}$ Textile Engineering department, Faculty of Engineering, Alexandria University, Alexandria, Egypt. \\ ${ }^{2}$ Mechanical Engineering department, Faculty of Engineering, Alexandria University, Alexandria, \\ Egypt \\ ${ }^{3}$ Material \& Manufacturing Engineering, Faculty of Engineering, Galala University, Galala City, \\ Egypt
}

\begin{abstract}
The factors of increasing productivity, reducing the cost and the quality improvement are the most important research concerns in weaving machinery. Increasing the effectiveness and productivity of production were achieved by increasing the operating time and efficiency of weaving looms. Thus, the manufacturers of weaving equipment attempt to minimize factors that limit production speed and production conditions. Heald frame is one of the known parts of the weaving machine that causes vibrations and noise which are important factors that influence high-speed development of looms. In this research work, study of mechanical factors (stresses and vibration) has been investigated for heald shaft. Finite element model of the heald frame was constructed to simulate different type of material. Then some important natural frequencies and vibration modes are calculated and the results. Results show a major improvement with the usage of these different material. As well as the failure of heald shaft is mainly due to friction and vibration and not due to the stresses or weight.
\end{abstract}

Keywords: heald frame, composite, carbon-fibre, glass-fibre, vibration, finite element, weaving machine

\section{INTRODUCTION}

It is fundamentally a known fact that the heald frames move constantly in a vertical reciprocated movement in order to raise the warp yarns to provide the interlacing with weft yarns. The minimum number of heald frames is two. In case of complex weaving patterns, more heald frames are required [1]. Consequently, the shedding motion and warp tension are strongly influenced by the heald shaft's motion. Looms should be equipped with more heald frames and moving at high speed [2]. Vibration of the heald frame may causes breakage of yarns and reduces weaving efficiency that leads to limiting and reducing the speed of the loom. So, a lot of researches have been done to develop and improve the performance of the heald shaft. The design and development of heald frame mechanism was carried out in Air-jet weaving machine in order to save energy newly developed high-volume-low-pressure relay nozzles had been used also for very high operating speeds [3,7]. The dynamic force of the heald is less than the resultant forces influencing the heald. Under the influence of pulling the warp ends down ward, the heald changes its movement direction and moves in the direction of the carrying healds movement[4].

Composite material was proposed to be used in manufacturing the heald frame. Composite materials are formed by combining two or more materials so that they have better engineering properties than conventional materials, e.g., metals. Some of the properties that can be improved by forming a composite material are hardness, strength, weight reduction, 
wear resistance, fatigue life and wear resistance. Composite materials are commonly formed in fibrous structure, which is made up of fibres and a resin as a matrix material $[5,6]$.

Thus, the aim of this work is to compare between the traditional heald frame that is used in industry and a modified heald frame made of composite material to reduce the stresses and vibration on heald shaft using different materials on the performance of the loom using simulation software - ABAQUS platform [8].

\section{MATERIALS}

The material properties which were used in this study are illustrated in table 1 and table 2. As well all the measurements and experiments in this research were performed on air jet weaving machine heald shaft frame.

Table 1. Material properties used in traditional model

\begin{tabular}{|c|c|c|c|}
\hline Material & $\begin{array}{c}\text { Modulus of elasticity } \\
\text { (MPa) }\end{array}$ & Poisson ratio & Density (tonne/ $\mathbf{m m}^{\mathbf{3}}$ ) \\
\hline Steel & 210000 & 0.3 & $7.874 \mathrm{E}-9$ \\
\hline Aluminium & 70000 & 0.34 & $2.7 \mathrm{E}-9$ \\
\hline
\end{tabular}

Table 2. Material properties used in modified model

\begin{tabular}{|c|c|c|c|c|c|c|c|c|c|c|}
\hline \multirow[b]{2}{*}{ Material } & \multirow{2}{*}{$\begin{array}{c}\text { Density } \\
\text { (tonne/mm³) }\end{array}$} & \multicolumn{3}{|c|}{ Modulus of elasticity } & \multicolumn{3}{|c|}{ Poisson ratio } & \multicolumn{3}{|c|}{ Shear modulus } \\
\hline & & $\begin{array}{c}\text { E1 } \\
\text { (GPa) }\end{array}$ & $\begin{array}{c}\text { E2 } \\
\text { (GPa) }\end{array}$ & $\begin{array}{c}\text { E3 } \\
\text { (GPa) }\end{array}$ & $\gamma 12$ & $\gamma 13$ & $\gamma 32$ & $\begin{array}{c}\text { G12 } \\
\text { (GPa) }\end{array}$ & $\begin{array}{c}\text { G13 } \\
\text { (GPa) }\end{array}$ & $\begin{array}{c}\text { G23 } \\
\text { (GPa) }\end{array}$ \\
\hline $\begin{array}{c}\text { Glass fibre } \\
\text { composite }\end{array}$ & 1.57778E-09 & 23.62 & 9.87 & 9.87 & 0.23 & 0.23 & 0.23 & 4.0 & 4.0 & 4.0 \\
\hline $\begin{array}{c}\text { Carbon fibre } \\
\text { composite }\end{array}$ & $1.56 \mathrm{E}-09$ & 136 & 11.9 & 11.9 & 0.29 & 0.29 & 0.4 & 4.86 & 4.86 & 4.4 \\
\hline
\end{tabular}

\section{FINITE ELEMENT MODEL (FEA) \& METHODOLOGY}

The modelling of the orthotropic materials was made using Abaqus CAE software to construct finite element model of the heald frame, the properties of materials used in structure of the old heald shaft frame as shown in table 1, the properties of materials used in structure of the new modelling of the heald shaft frame via Abaqus software is shown in table 2. Figure 1 illustrate the model of conventional heald shaft frame that is used in industry, with length of $2000 \mathrm{~mm}$, height $550 \mathrm{~mm}$ and thickness $20 \mathrm{~mm}$. Assuming the motion of heald shaft frame is a simple harmonic motion with maximum displacement $80 \mathrm{~mm}$ and dwell period of 120 degree. Figure 2 illustrates the part meshing shape of heald shaft frame.

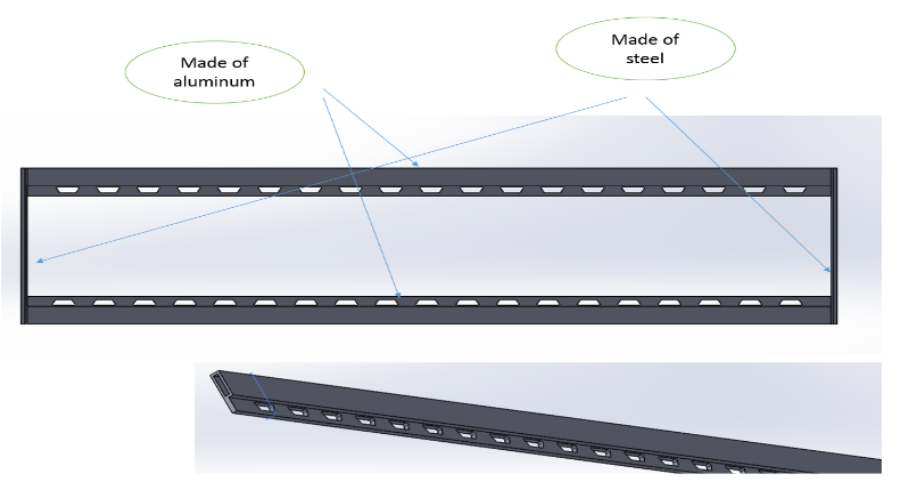

Figure 1. The model of conventional heald shaft frame 


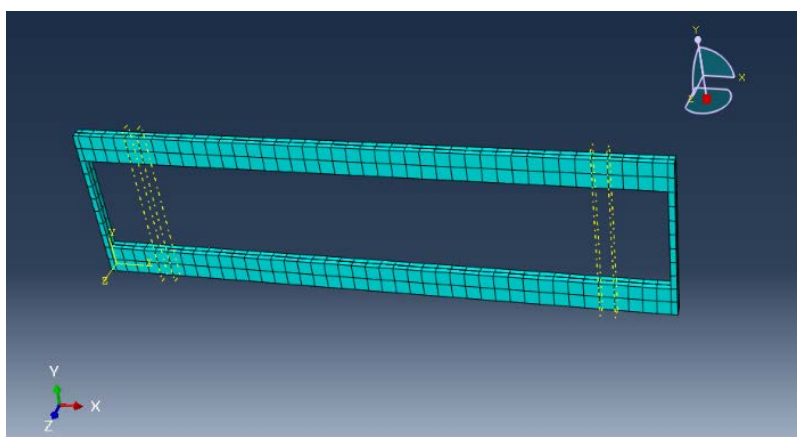

Figure 2. The part meshing shape of heald shaft frame

Figure 3. shows the arrangements of the various composite layup and the orientation of the fibres, the composite layup is shown for zero-degree, forty-five-degree, ninety-degree, forty-five-degree, zero-degree, forty-five-degree, ninety-degree, forty-five degree, and zerodegree. The model consists of nine laminae.
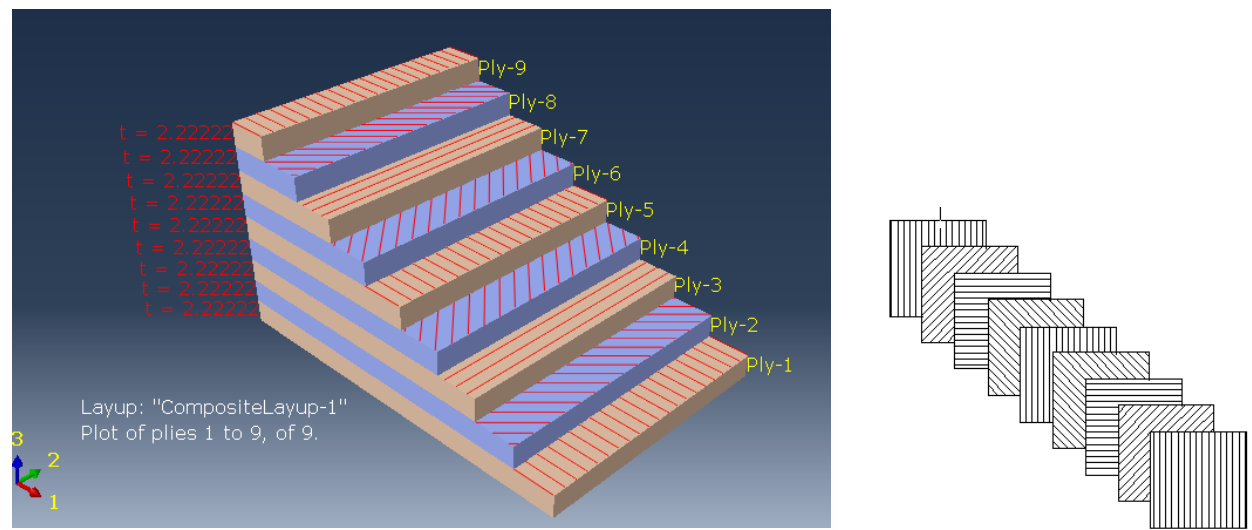

Figure 3. The arrangements of the various composite laminates

\section{RESULTS}

The following part enlightens the results obtained from the analysis of finite element design of heald frame.

\subsection{Stresses}

Figure 4 illustrates the stress analysis of the heald shaft made of aluminium alloy, the maximum stress obtained was $24.68 \mathrm{MPa}$ concerted at the side edges of heald frame. Figure 5 shows the stresses analysis of the heald shaft made of glass fibre; the maximum stress obtained was 9.064 MPa concerted at the side edges of heald frame. Figure 6 displays the stresses analysis of the heald shaft made of carbon fibre, the maximum stress obtained was 7.78 MPa concerted at the upper middle part of heald frame. All the obtained results of the stresses were within the design factor of safety. 


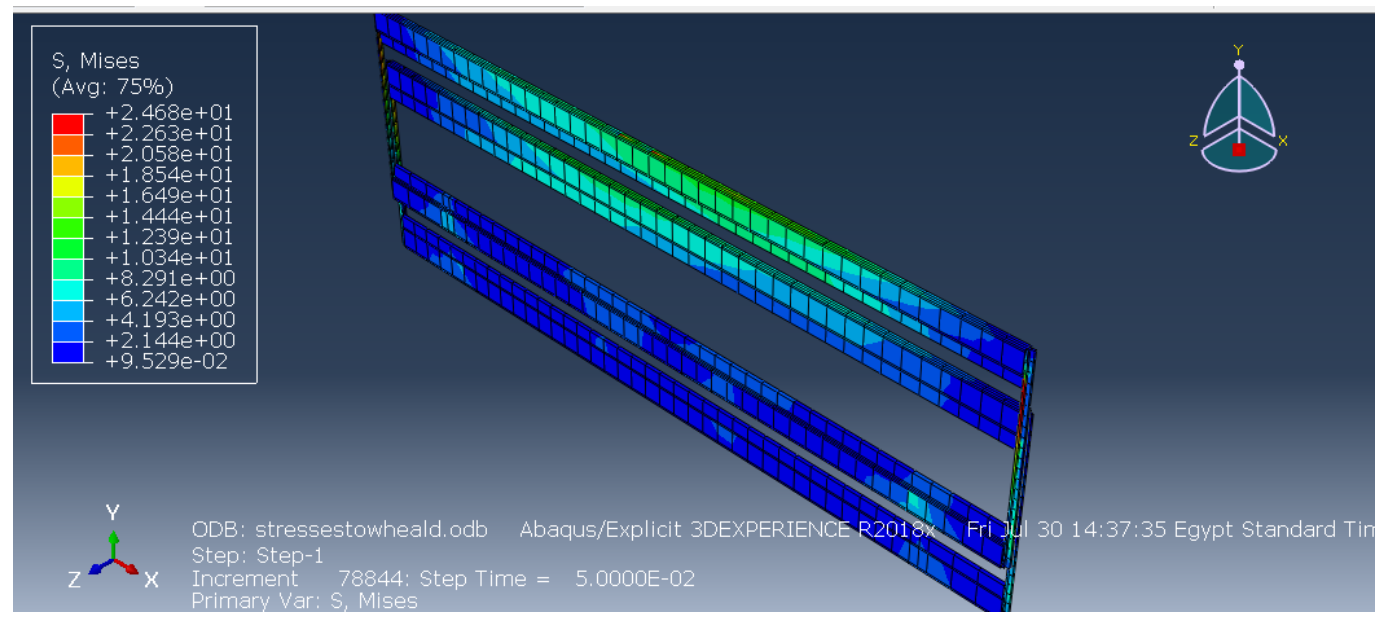

Figure 4. The maximum stress of heald shaft made of aluminium alloy

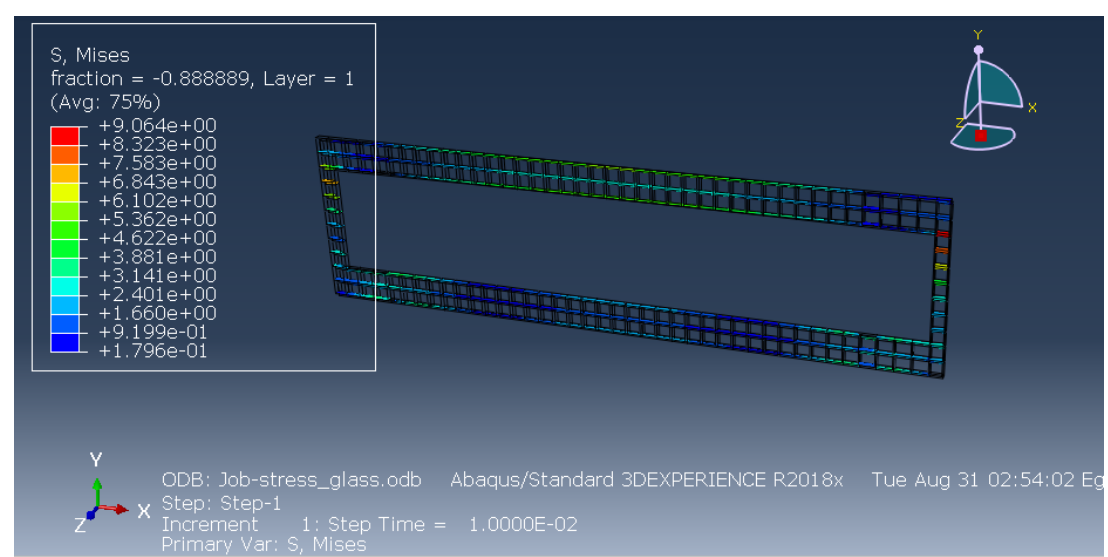

Figure 5. The maximum stress of heald shaft made of composite of glass-fibre

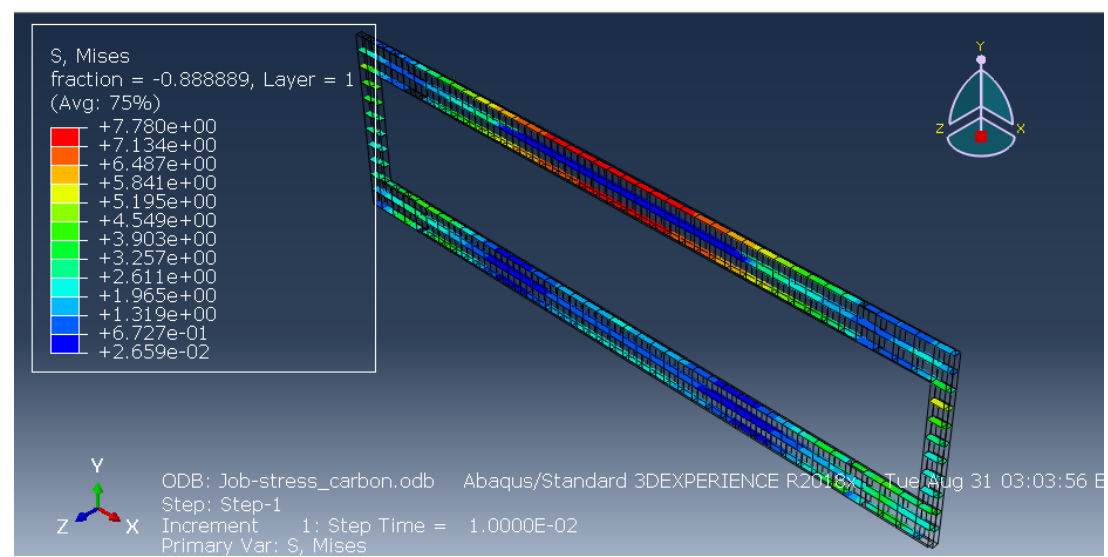

Figure 6. The maximum stress of heald shaft made of composite of carbon-fibre

\subsection{Vibration}

Figure 7 shows the natural frequency analysis of the heald shaft made of aluminium alloy; the natural frequency obtained was $14.76 \mathrm{~Hz}$. Figure 8illustrates the natural frequency analysis of the heald shaft made of glass fibre the natural frequency obtained was $9.064 \mathrm{~Hz}$. Figure 9 demonstrates the natural frequency analysis of the heald shaft made of carbon fibre the natural frequency obtained was $7.78 \mathrm{~Hz}$. Results show low frequency range for composite material which requires more research work. 


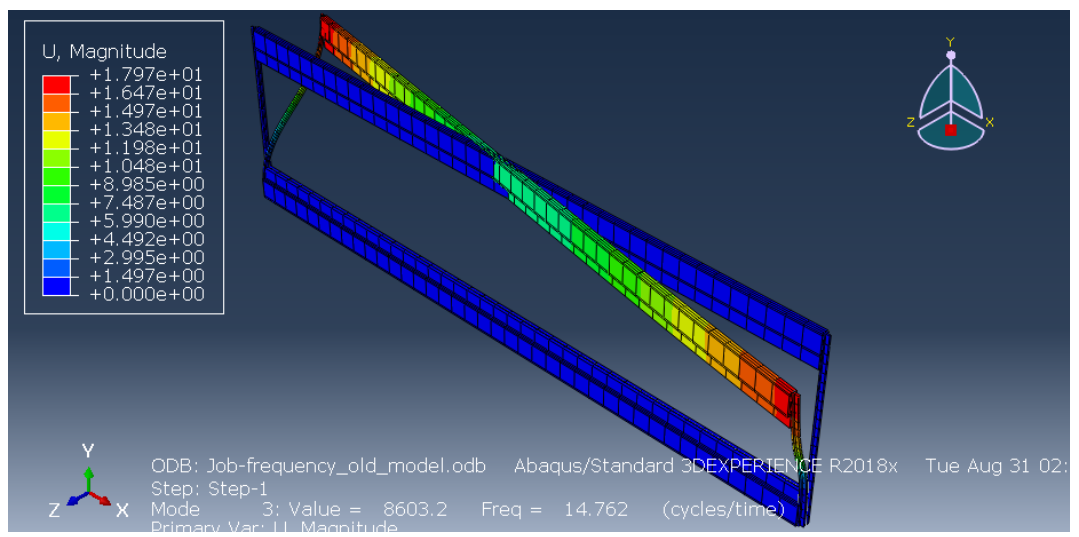

Figure 7. The Natural frequency of heald shaft made of aluminium alloy

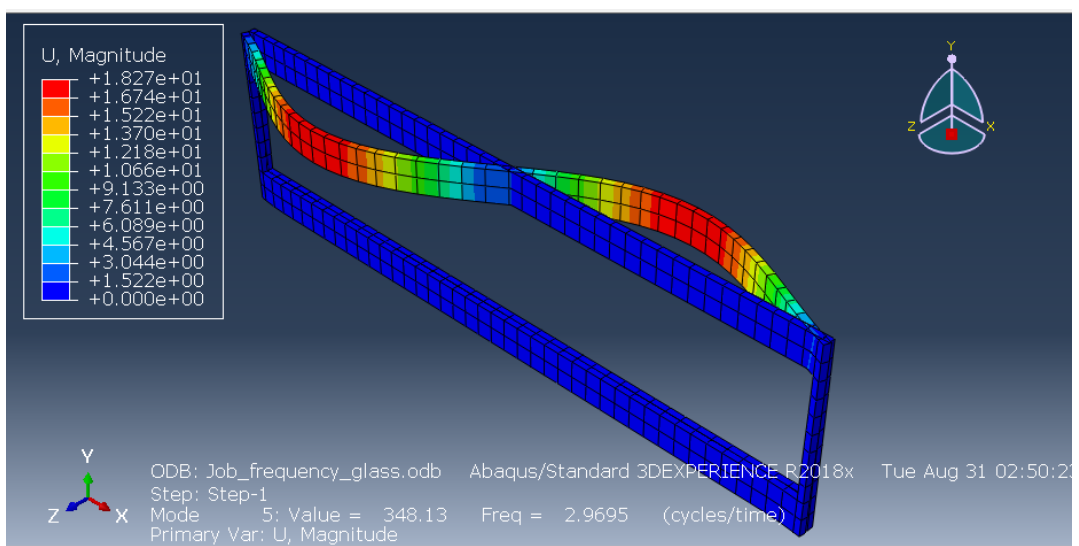

Figure 8. The Natural frequency of heald shaft made of Glass fibre composite

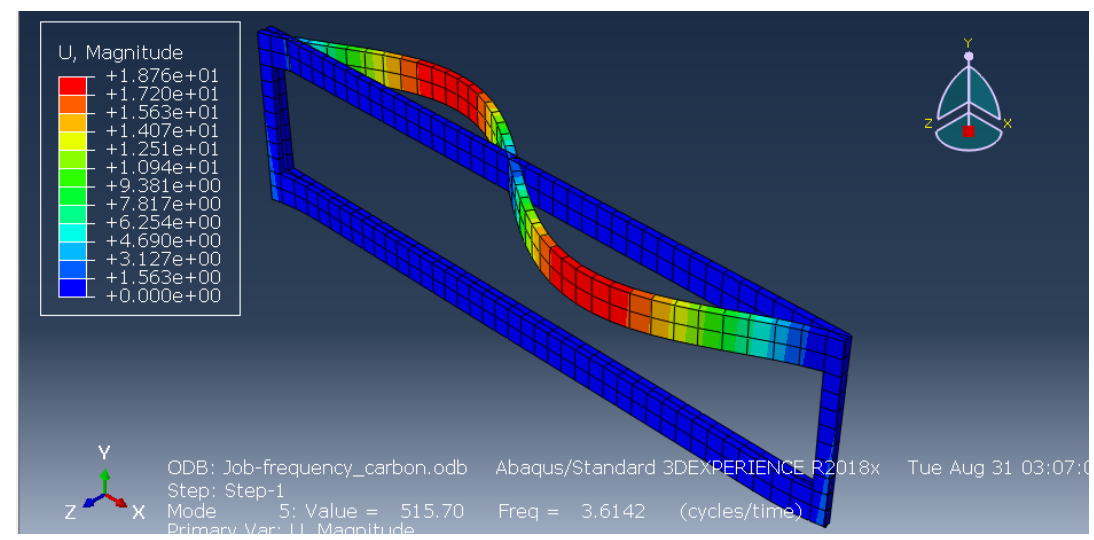

Figure 9. The Natural frequency of heald shaft which made of carbon fibre composite

Table 3 demonstrates the comparison between the results of traditional heald frame made of aluminium and the modified model made from glass and carbon composite material. Figure 10 presents the comparison of natural frequency between traditional heald shaft and modified model made from glass and carbon composite material. Figure 11 illustrates the comparison of stresses between traditional heald shaft and the modified model made from glass and carbon composite material.

Table 3. Natural frequency and the stresses of two type of models

\begin{tabular}{|c|c|c|c|}
\hline Materials & Aluminium alloy & Glass fibre composite & Carbon fibre composite \\
\hline Frequency $(\mathrm{Hz})$ & 14.76 & 2.96 & 3.61 \\
\hline Stresses $(\mathrm{MPa})$ & 24.68 & 9.064 & 7.78 \\
\hline
\end{tabular}




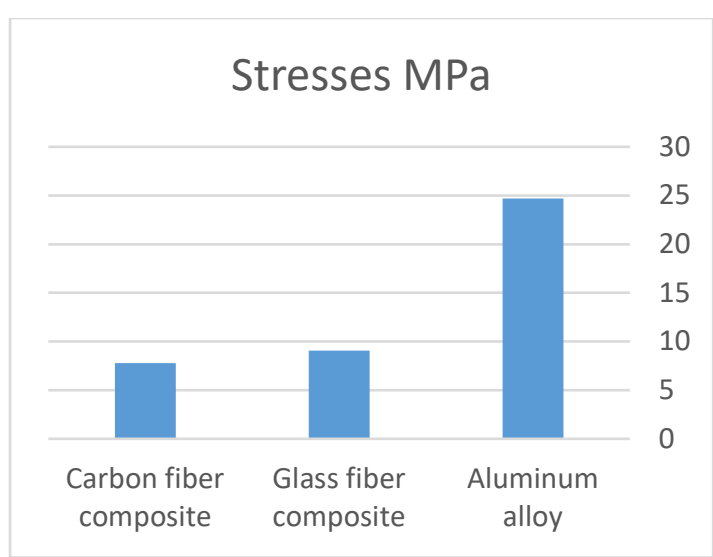

Fig. 10. The comparison of natural frequency

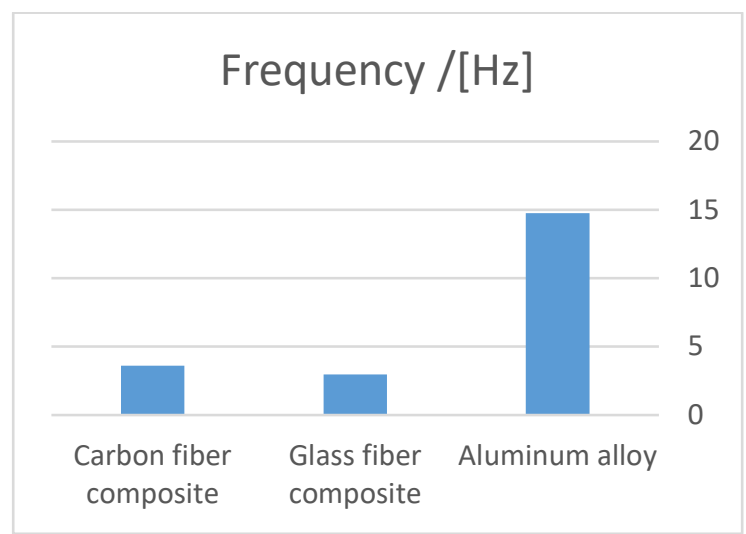

Fig. 11. The comparison of the stresses

As seen from figures 10 and 11, when the composite of carbon-fibre and the composite of glass-fibre were used as the material of heald frame, the natural frequency obviously decreased compared to aluminium alloy material. The smallest value makes fundamental frequency of heald frame decreased to $2.96 \mathrm{~Hz}$. that is less than $11.8 \mathrm{~Hz}$. of the aluminium alloy material, leading to the reduction of the loom's speed. Also, the stresses decreased obviously relative to aluminium alloy material.

\section{CONCLUSIONS}

The study estimates the dynamic nature of the movement of the heald shaft with relative to each other. For predicting low stresses, a computer program based on this model was developed. The finite element model of heald frame with composite of carbon-fibre and glass-fibre were constructed. The stresses obtained from the Abaqus is very low compare to the maximum load from yarn tension during operation case, therefore, the heald shaft is recommended to be made from another material. The composite model provided low cost and low strength, but the fundamental frequency of this method is decreased by $11.8 \mathrm{~Hz}$ to that of the heald frame with aluminium alloy. So, the vibration in working condition of looms is effectively decreased.

\section{REFERENCES}

[1] Hall, A.J., The Standard Hand book of Textiles, $8^{\text {th }}$, 1975

[2] Gokarneshana, N., Jegadeesan, N., Dhanapal, P., Recent innovations in loom shedding mechanisms, In: Indian Journal of Fibre \& Textile Research, 2010, 35, 85-94 
[3] Koç, E., Çinçik, E., Analysis of Energy Consumption in Woven Fabric, In: Production. FIBRES \& TEXTILES in Eastern Europe, 2010, 18, 2, 79, 14-20

[4] Bílek, M., Kováŕ, S., Skřivánek, J., Mathematical modelling of the heald shaft, In: Autex Research Journal, DOI: 10.1515/aut-2015-0041

[5] Rao, K.S., Mahendra, M., Aithal, K., Study of Composite Glass Laminate Reinforced with Carbon Fiber at Cutout Locations, In: American Journal of Materials Science, 2017, 7, 5, 170-173

[6] Haifei, O., Songlin, W.Y.W., The Study on Dynamic Characteristics for Heald Frame Designed by new Type Composite of Carbon-Fibre, In: Advanced Materials Research, 2013, 804, 353-357

[7] Schwarzfischer, F., Kurtenbach, S., Onischke, J., Corves, B., Design and Development of a Heddle Shaft Mechanism for Air-Jet Weaving Machines

[8] Abaqus Cae, Available at: https://edu.3ds.com/en/software/abaqus-student-edition [Accessed on June 2021] 